\title{
L'Automne, études rassemblées et présentées par Alain Montandon
}

\section{Philippe Andrès}

\section{(2) OpenEdition}

1 Journals

Édition électronique

URL : http://journals.openedition.org/studifrancesi/8281

DOI : 10.4000/studifrancesi.8281

ISSN : 2427-5856

Éditeur

Rosenberg \& Sellier

\section{Édition imprimée}

Date de publication : 1 mai 2009

Pagination : 181-182

ISSN : 0039-2944

\section{Référence électronique}

Philippe Andrès, «L'Automne, études rassemblées et présentées par Alain Montandon », Studi Francesi [En ligne], 157 (LIII | I) | 2009, mis en ligne le 30 novembre 2015, consulté le 09 janvier 2021. URL:

http://journals.openedition.org/studifrancesi/8281 ; DOI : https://doi.org/10.4000/studifrancesi.8281

Ce document a été généré automatiquement le 9 janvier 2021.

\section{cc)}

Studi Francesi è distribuita con Licenza Creative Commons Attribuzione - Non commerciale - Non opere derivate 4.0 Internazionale. 


\title{
L'Automne, études rassemblées et présentées par Alain Montandon
}

\author{
Philippe Andrès
}

\section{RÉFÉRENCE}

L'Automne, études rassemblées et présentées par Alain MONTANDON, Université Blaise

Pascal, Centre de Recherches sur les Littératures Contemporaines, Presses

Universitaires Blaise Pascal, Clermont-Ferrand, 2006, pp. 485.

1 Cet ouvrage, agréable à lire, se présente comme une série d'articles sur la thématique de l'automne et le principal défi relevé a consisté à revisiter, en dehors de tout cliché, comme le signale Alain MONTANDON dans la préface (pp. 7-17), ce «sentiment du vieillir, celui du passage de la vie et des choses devant les inévitables transformations et métamorphoses infligées par le temps» (p. 7).

2 Nous limitant aux articles consacrés aux auteurs du XIX siècle, nous avons retenu la contribution claire et synthétique de Cécile MeYnARD (pp.61-76), qui souligne le paradoxe d'une écriture féminine romantique révélant un manque d'intérêt pour l'automne. Cependant le symbole évolue positivement, notamment dans les années 1820 , avec le concept balzacien de «femme de trente ans», «à la fois jeune et vieille, innocente et expérimentée» (p.65). Alex LASCAR propose une suite intéressante de micro-analyses de passages de l'œuvre de Balzac, comme autant de tableaux des diverses métamorphoses subtiles des «automnes balzaciens» (pp.77-92). Mustapha TRABELSI offre une analyse fine et pertinente des «palimpsestes chronologiques et spatiaux» (p. 365) du «feuilleté automnal des Mémoires d'outre-tombe de Chateaubriand» (pp.363-376), tant d'un point de vue stylistique qu'existentiel: le paysage se métamorphose ainsi en «pure création esthétique» (p.371). Pour sa part, Joanna Augustyn invite à relire "Le Rhin de Victor Hugo et les lettres de septembre» (pp. 399-410) en liant le thème hugolien des saisons à un «imaginaire associé à l'histoire» (p. 401). Enfin, François KeRLouÉGAN, dans «L'écho perdu de la jeunesse»: 
l'automne dans "Volupté" de Sainte-Beuve (pp.423-433), réussit à nous convaincre de l'importance de «la poétique romanesque de l'automne romantique» (p.423). Il cerne avec finesse les «isotopies du discontinu et de l'indistinct» (p.425) et son goût pour la formule poétique démontre que, révélant le moi dans une sorte d' «épiphanie de la conscience» (p.428), «l'automne beuvien est un écran» (p. 430) du «véritable sujet du roman», la littérature (p. 432).

3 Les dix-neuviémistes pourront donc lire cet ouvrage avec intérêt puisque un certain nombre de contributions s'attachent à examiner la thématique de l'automne d'un œil nouveau. Cependant, les comparatistes et les amateurs de littérature du $\mathrm{xx}^{\mathrm{e}}$ siècle pourront également se délecter à la lecture d'un volume qui invite à se pencher sur une part intime de chacun d'entre nous: notre relation au temps qui passe! 